\title{
Cancer Mortality Among Woodworkers
}

\author{
Steven D. Stellman, PhD, and Lawrence Garfinkel, MA
}

\begin{abstract}
The mortality experience of 10,322 men employed in woodworking industries was compared with that of 406,798 nonwoodworkers. All subjects were enrolled in an American Cancer Society study and followed prospectively from 1959 through 1972. Age-adjusted rates of death from all causes and from all cancers were not higher in the woodworker group, but excess rates were observed for cancers of the lung, stomach, and bladder, as well as nonmelanoma skin cancer and possibly leukemia. Woodworkers experienced significantly decreased rates of colon-rectum cancer and coronary heart disease. The elevated cancer rates could not be explained by cigarette smoking habits. If anything, there is evidence to suggest a possible interaction between employment in woodworking trades and heavy cigarette smoking, in increasing the risk of lung and bladder cancer.
\end{abstract}

Key words: cancer, woodworking, carpentry, follow-up studies, cigarettes

\section{INTRODUCTION}

Since the beginning of the Industrial Revolution, but particularly during the 20 th century, two significant developments in the way wood is handled prior to and during manufacturing processes are thought to have had significant potential health effects. The first is the use of high-speed saws and drills, which generate large quantities of very fine, respirable wood dust, including discrete but microscopic wood particles, as well as vapors from volatile oils and natural organic volatile material. The second is the use of a wide variety of chemicals to preserve raw lumber from rot, insects, and discoloration, as well as innumerable solvents, varnishes, glues, and resins in manufacturing and finishing of end products.

Table I lists many known toxic agents which have been in widespread use in wood industries. This list includes known human carcinogens such as asbestos, which permeates the entire construction industry, as well as arsenic and chromium compounds. Also included are formaldehyde, which causes squamous carcinomas of the nasal cavity in rats [Swenberg et al, 1980], and a variety of chlorophenols, such as PCP, which have often been contaminated with highly toxic and carcinogenic dioxins. A comprehensive review of these chemicals and their carcinogenic and other toxic properties has been published by IARC [1981].

During the past 25 years, a number of cancers have been associated with occupational exposure to wood dust. Adenocarcinoma of the nasal cavity is firmly

American Cancer Society, New York.

Address reprint requests to Steven D. Stellman, American Cancer Society, 4 West 35 th Street, New York, NY 10001.

Accepted for publication September 5, 1983.

1984 Alan R. Liss, Inc. 
TABLE I. Toxic Exposures in Woodworking Jobs

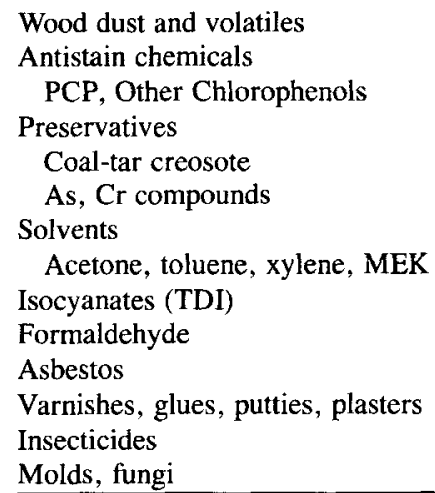

established as causally related to wood dust exposure, especially in studies done in England [Hadfield and Macbeth, 1971; Hadfield, 1972; Acheson, 1976; Acheson et al, 1981], but also in a number of American [Brinton et al, 1977; Roush et al, 1980], Canadian [Elwood, 1981], and European [Olsen et al, 1979; Cecchi et al, 1980] studies.

Other cancers which have variously been associated with occupation in woodrelated industries are stomach [Milham, 1974], lung [Harrington et al, 1978; Blot et al, 1982], and bladder cancer [Wynder and Goldsmith, 1977], as well as Hodgkin disease [Milham and Hesser, 1967; Petersen and Milham, 1974; Fonte et al, 1982; Greene et al, 1978] and histiocytic lymphomas and soft-tissue sarcomas [Hardell, 1979; Hardell and Sandstrom, 1979].

Publication of the IARC review, as well as other recent studies, prompted us to review our existing data to see whether these associations could be confirmed, as well as to generate new hypotheses.

\section{MATERIALS AND METHODS}

Starting in October 1959, more than one million men and women in 1,121 counties in 25 states were enrolled in a prospective epidemiologic study. They were asked to complete a detailed four-page confidential questionnaire on family history, history of diseases, present physical complaints, occupational exposures, and a number of habits including eating, drinking, and smoking. The questionnaires were obtained by 68,000 American Cancer Society volunteers who were asked to enroll people they knew well and would be able to report on over the next several years. Enrollment was by households, with at least one member of the household over the age of 45 years.

Each year, the volunteers were asked to report whether the persons they had enrolled were alive or dead; if a person had died, the volunteer entered the date and place of death. They were also asked to supply information on changes of address, or changes of name by marriage.

Tracing was done annually for 6 years. In 1966, after six follow-ups, the tracing was discontinued; at that time, $98.4 \%$ of the subjects had been successfully traced. The decision was made to resume tracing in 1971 and again in 1972. Follow-up through June 30, 1972 resulted in successful tracing of $92.8 \%$ of the subjects. 
A death certificate was requested from the appropriate State or Provincial health department for every person reported to have died. The cause of death was coded based on the listed underlying and contributing causes, according to the rules of revision 7 of the International Classification of Diseases. During the first 6 years of the study, physician or hospital confirmations of causes of death were sought whenever cancer was mentioned on the death certificate. This additional information was received for about $90 \%$ of the cancers. Thus, in this period (1960-66) the cause of death is based on "best evidence" available. This supplementary information was used to verify the site of cancer only. We did not evaluate specimens pathologically, and do not therefore attempt to differentiate between histological types (eg, squamous cell vs adenocarcinoma of the lung), nor between acute and chronic forms of leukemia. Further details of the study have been published previously [Hammond, 1966; Hammond and Garfinkel, 1969].

Woodworkers were identified on the basis of their answer to the question: "What is your present occupation? If retired, what was your previous occupation?" Woodworkers were defined as those whose occupations fell in a list of 33 job titles, including woodworker, carpenter, joiner, sawmill operator, lumberyard foreman, furniture repairer, etc. Subjects in these detailed categories were aggregated to form the three major wood-related categories treated in the IARC monograph [IARC, 1981]: carpentry and joinery, lumber and sawmill, and furniture and cabinetry. The numbers of workers in these categories and some of their sub-specialties are shown in Table II.

This method of identification of occupational "exposure"-namely, self-identification as a woodworker-distinguishes this study from those in which occupation is determined from a death certificate. Our scheme has the advantage that it is based on the subject's first-hand assessment of his own job, and that the encoding of the exposure category (woodworker or nonwoodworker) was done prospectively by coders who were blind to the eventual outcome for each subject. On the other hand, the scheme is potentially less precise than one in which occupational classification could be made by an industrial hygienist observing each worker, as is done in some cohort studies of specific industries. Exposures to specific levels of wood dust, or to

TABLE II. Occupational Specialties of Woodworkers

\begin{tabular}{|c|c|c|c|}
\hline Specialty & No. & No. & Percent \\
\hline Carpentry and joinery & & 7,157 & $69.3 \%$ \\
\hline Carpenters & 6,184 & & \\
\hline Joiners and finishers & 206 & & \\
\hline Pattern makers & 80 & & \\
\hline Lumber and sawmill & & 2,409 & $23.3 \%$ \\
\hline Lumber "business" & 536 & & \\
\hline Sawmill operator or filer & 458 & & \\
\hline Logger, lumberjack & 401 & & \\
\hline Furniture and cabinetry & & 735 & $7.1 \%$ \\
\hline Cabinetmaker & 357 & & \\
\hline $\begin{array}{l}\text { Furniture maker, } \\
\text { manufacturer, refinisher }\end{array}$ & 274 & & \\
\hline Multiple & & 21 & $0.2 \%$ \\
\hline Total & & 10,322 & \\
\hline
\end{tabular}


specific types of wood, such as hard and soft woods, are not known. Nevertheless, most self-described occupations were unambiguously precise (two-thirds simply stated "carpenter"), and the likelihood that subjects were incorrectly classified in the three main wood industries is very small.

We do not know the duration of work in wood industries for any subjects. We are relying on age as the only available surrogate variable. Subjects who described themselves as woodworkers at the time of filling out the questionnaire could have held one or many other occupations during their lives.

For the purpose of this analysis, all male subjects are included who 1) answered "no" to the question "Are you sick at the present time?" and who 2) were alive on July 1,1960 . The first condition serves to eliminate a subgroup of the study population that has an exceptionally high death rate. The second condition provides a uniform starting date for the period of observation, and also serves to eliminate sick persons.

The standard mortality ratio (SMR) method is the main statistical method for assessing associations between exposure and outcome. Person-years of exposure (PYE) to risk (of dying) are calculated for each individual, beginning July 1, 1960, until date of death, withdrawal alive on June 30, 1972, or loss to follow-up. A cohort age analysis is used. In this type of analysis, PYE are stratified by 5-year age groups (which are equivalent to 5-year birth cohorts, since all subjects were enrolled at about the same time), by calendar period of observation (1960-66 and 1966-72), and by any other desired control variables, such as cigarette smoking. Obviously, stratification by occupational category is done as well. The total number of woodworker deaths observed in all strata, $\mathrm{O}$, is divided by the total number expected, $\mathrm{E}$ (based on nonwoodworker rates in the same set of strata). The SMR is $100 \times 0 / \mathrm{E}$. The Poisson statistic is used for significance testing.

\section{RESULTS}

\section{Number of Subjects}

There were 406,798 nonwoodworkers $(4,130,217$ person-years) and 10,322 woodworkers (102,062 person-years) in our study population. Over two-thirds of the latter were carpenters or joiners, $23.3 \%$ were in the lumber and sawmill industry, $7.1 \%$ in the furniture and cabinetry industry, and a trivial number in more than one category. The numbers of workers in the most common suboccupations are given in Table II.

\section{Residence}

By and large, the home residence of the woodworkers reflected that of the other male subjects enrolled, with these notable exceptions (Table III): More woodworkers came from Oregon than any other state, California ranked second in woodworker population but first in overall study population, and Minnesota ranked third for WW, but sixth for NWW.

\section{Age}

Table IV shows the distribution of age and several other demographic variables. The woodworker group was significantly older as a whole than the nonwoodworkers (mean age 56.6 compared to 54.2 years), and was substantially less well educated. As expected from the greater age of the WW group, a greater proportion reported 
TABLE III. State of Residence of Subjects

\begin{tabular}{|c|c|c|c|c|c|c|}
\hline \multirow[b]{2}{*}{ State } & \multicolumn{3}{|c|}{ Nonwoodworkers } & \multicolumn{3}{|c|}{ Woodworkers } \\
\hline & Rank & No. & $\%$ & Rank & No. & $\%$ \\
\hline California & 1 & 44,865 & 11.0 & 2 & 1,237 & 12.0 \\
\hline Pennsylvania & 2 & 37,432 & 9.2 & 4 & 745 & 7.2 \\
\hline Ohio & 3 & 34,191 & 8.4 & 7 & 647 & 6.3 \\
\hline Illinois & 4 & 31,161 & 7.7 & 5 & 722 & 7.0 \\
\hline New York & 5 & 30,185 & 7.4 & 6 & 701 & 6.8 \\
\hline Minnesota & 6 & 29,271 & 7.2 & 3 & 1,010 & 9.8 \\
\hline Iowa & 7 & 15,288 & 3.8 & 11 & 370 & 3.6 \\
\hline Virginia & 8 & 15,000 & 3.7 & 8 & 500 & 4.8 \\
\hline Florida & 9 & 14,963 & 3.7 & 9 & 492 & 4.8 \\
\hline Texas & 10 & 15,048 & 3.7 & 14 & 284 & 2.8 \\
\hline Oregon & 14 & 10,697 & 2.6 & 1 & 1,313 & 12.7 \\
\hline
\end{tabular}

TABLE IV. Distribution of Variables Among Nonwoodworkers (NWW) and Woodworkers (WW)

\begin{tabular}{lrr}
\hline & NWW \% & WW \% \\
\hline Age at entry & & \\
$30-49$ & 34.7 & 29.0 \\
$50-59$ & 37.3 & 33.1 \\
$60-69$ & 19.8 & 24.3 \\
$70+$ & 8.1 & 13.7 \\
Mean & 54.2 & 56.6 \\
Retired & & \\
Yes & 11.3 & 17.3 \\
No & 87.9 & 82.9 \\
Birthplace & & \\
U.S. & 92.7 & 90.7 \\
Eastern Europe & 1.1 & 0.8 \\
Scandinavia & 0.6 & 2.4 \\
Education & & \\
Grammar school & 23.0 & 43.0 \\
Some high school & 20.2 & 26.7 \\
High school graduate & 18.0 & 15.5 \\
College & 37.8 & 13.4 \\
Smoking habits & & \\
Never smoked regularly & 21.8 & 23.1 \\
Cigarettes only & 45.2 & 44.8 \\
Cigarettes plus other & 21.7 & 21.0 \\
Cigar or pipe only & 11.1 & 10.9 \\
No. cigarettes per day & & \\
(current smokers only) & & \\
1-9 & 6.8 & 6.7 \\
10-19 & 12.2 & 13.2 \\
20 & 22.9 & 24.9 \\
21-39 & 11.8 & 9.7 \\
$40+$ & 7.9 & 5.9 \\
\hline
\end{tabular}


they were retired (17.3\% vs $11.3 \%$ of NWW). In addition, $2.4 \%$ of the WW group were born in Scandinavia, compared to $0.6 \%$ of the NWW, which probably reflects the large enrollment from Minnesota.

\section{Smoking and Other Confounding Variables}

Smoking distributions of the WW and NWW groups were similar, both in respect to use of cigarettes, cigars, and pipes, and in numbers of cigarettes smoked by current users: $44.8 \%$ of WW and $45.2 \%$ of NWW were exclusively cigarette smokers (current or former), and $23.1 \%$ of WW and $21.8 \%$ of NWW claimed never to have smoked regularly. The remainder in each group were pipe or cigar smokers, or combined pipes or cigars with cigarettes. The distributions of many other potentially confounding variables were extremely similar in WW and NWW. For example, the two groups had similar patterns of consumption of aspirin, use of over-the-counter medications such as tranquilizers, laxatives, and antacids, and beer consumption.

\section{Standard Mortality Ratios}

Increases. Neither the woodworker subgroups nor the WW as a whole experienced an excess overall death rate, or excess deaths from all cancers compared to the remainder of the study population (Table V). However, elevated death rates in the total WW group were found for cancers of the stomach and bladder, and for pneumonia $(\mathrm{p}<0.05)$. The stomach cancer excess was confined to the carpentryjoinery group. Carpenters and joiners also experienced excess lung cancer, nonmelanoma skin cancer, and leukemia. Elevated SMRs for bladder cancer were suggested among lumber/sawmill workers and furniture/cabinetry workers, but the numbers of deaths were small, and the SMRs were not statistically significant. A slight excess of accidental deaths in the total WW group was mainly attributable to 23 deaths among the lumber/sawmill group $(\mathrm{SMR}=147, \mathrm{p}<0.05)$. Six of these accidental deaths were in men specifically described as "sawmill operators" ( 3 expected, $\mathrm{p}=0.08$ ), which is consistent with other reports in this extremely hazardous industry [Milham, 1976].

Two cases of cancer of the nasal cavity were recorded among carpenters and joiners. The number is too small to make a statistical test meaningful, but is more than three times the expected number.

Decreases. Significantly lower rates were found among WW for cancer of the colon and rectum, and for coronary heart disease. The decrease in heart disease was seen only in carpenters and joiners, but all three subgroups had similar low rates of colon-rectum cancer. We failed to observe a hypothesized increase in Hodkin disease, as has been seen in other studies [Milham and Hesser, 1967; Petersen and Milham, 1974; Fonte et al, 1982; Greene et al, 1978], or, in fact, in any of the lymphatic cancers. If anything, these cancer rates were lower than expected, with three deaths from Hodgkin disease (4.5 expected), and 17 deaths from non-Hodgkin lymphomas (24.4 expected, $\mathrm{p}=0.075$ ).

\section{Adjustment for Smoking Habits}

There is frequently suspicion in any study that observed increases in lung cancer could be associated with smoking. We have approached this problem in three ways. The first was to calculate smoking-age-calendar period specific death rates from various causes for the NWW group, and apply them to the PYE of the WW group, to obtain expected numbers of deaths. These E's were summed over all smoking 
categories, and divided into the corresponding sum of O's, to obtain a "smokingadjusted" SMR. In these calculations, subjects were classified as either never smoked regularly; current smokers of $1-19,20,21-39$, or 40 or more cigarettes per day; current pipe or cigar smokers; or former smokers, for a total of seven categories.

Smoking-adjusted SMRs are shown in Table VI. If smoking is a confounding variable, one expects a high SMR to be reduced (or a low SMR to be increased) toward 100 - that is, in the direction of no association. Of the known tobacco-related cancers, only stomach cancer had its SMR reduced by this procedure, which seems to indicate that some, but by no means all, of the finding of increased stomach cancer was related to cigarette smoking confounding. This was to be expected, since both smoking and stomach cancer in this population were greatest at the lowest educational level. While the SMR for stomach cancer was further reduced by a small amount upon additional adjustment for education, the number of observed stomach cancer deaths among woodworkers still exceeded the expected value based upon age- and smoking-specific NWW rates in each of the four strata: grammar school only, some high school, high school graduate, college and above.

The SMR for colon-rectum cancer, which is not smoking-related and which was significantly below 100 before adjustment, was decreased even further after adjustment for smoking. This decrease is most likely related to differences in socioeconomic levels between WW and NWW.

To take another approach, smoking-specific expected deaths were computed for lung and bladder cancer, based upon the rates for nonwoodworkers who smoked exactly 20 cigarettes per day (Figs. 1,2). If there were no association between woodworking occupations and either lung or bladder cancer rates, then one would expect the heights of the bars in each group (ie, at each level of cigarette consumption) to be approximately the same. We see, in fact, that there is little difference in lung or bladder cancer risk between WW and NWW in the groups who smoked less than one pack of cigarettes per day, but that at one pack and over, the excess lung and bladder cancer risk is pronounced.

In another view of the same data (Figs. 3, 4), subjects have been grouped into smokers of less than a pack a day, exactly one pack, and more than one pack. In each of these three smoking categories, the NWW were considered the standard population. Little difference between WW and NWW (or between carpenters and joiners and NWW) was seen in the lowest smoking category, but the excess of WW over NWW increased as daily cigarette quantity increased. These data suggest to us that the increased lung and bladder cancer rates in WW, as compared to NWW in our study population, were due not so much to smoking in itself, but more likely to an interaction between cigarette smoking and woodworking-related exposures.

\section{DISCUSSION}

Our findings of moderately elevated risks for lung, bladder, and stomach cancer in our population of over 10,000 woodworkers are consistent with a number of population-based studies in the U.S. and U.K. For example, the Registrar-General [Logan, 1982] has reported statistically significant lung cancer SMRs for carpenters and joiners in each of the last three decennial reports: $1951-\mathrm{SMR}=104, \mathrm{p}<0.05$; $1961-\mathrm{SMR}=109, \mathrm{p}<0.05 ; 1971-\mathrm{SMR}=120, \mathrm{p}<0.01$. 


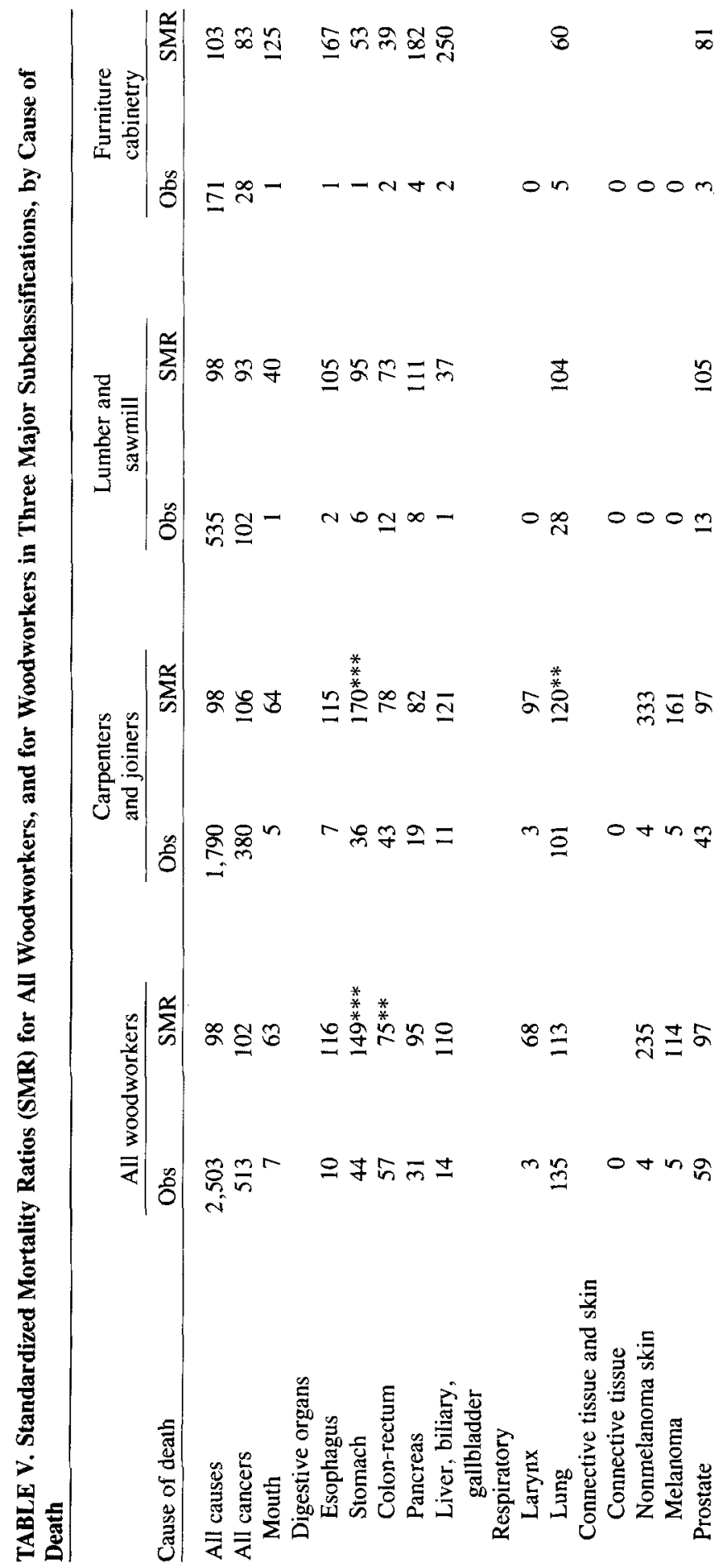




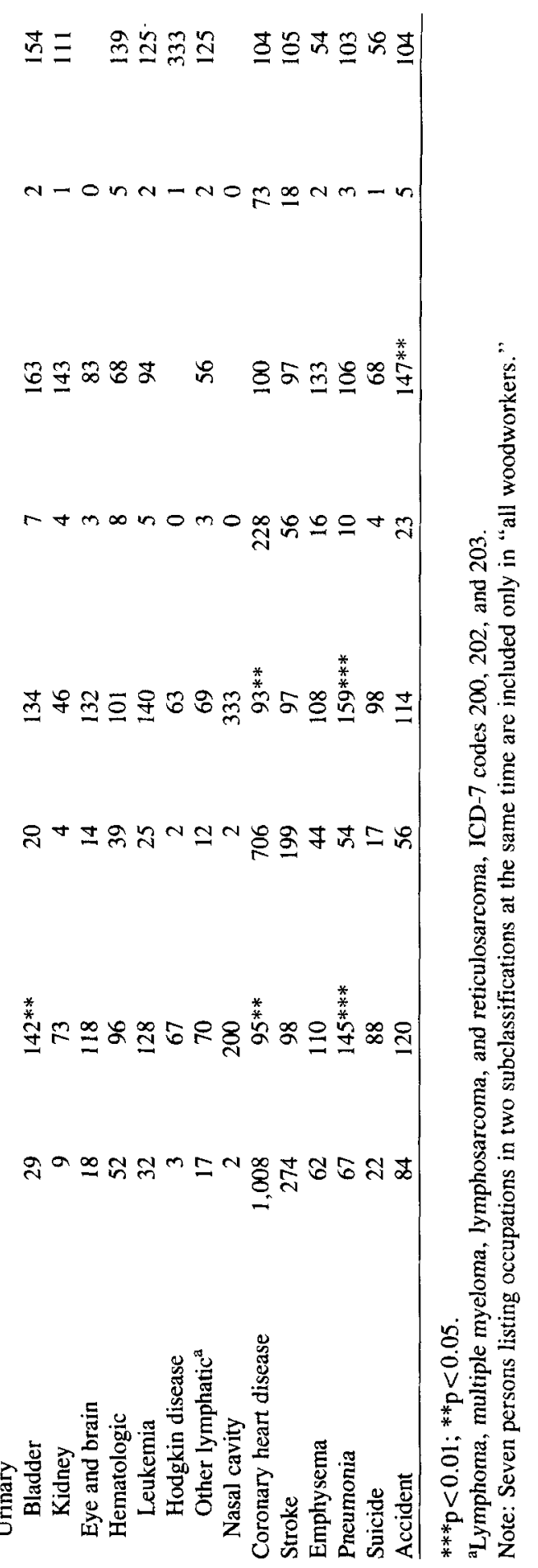




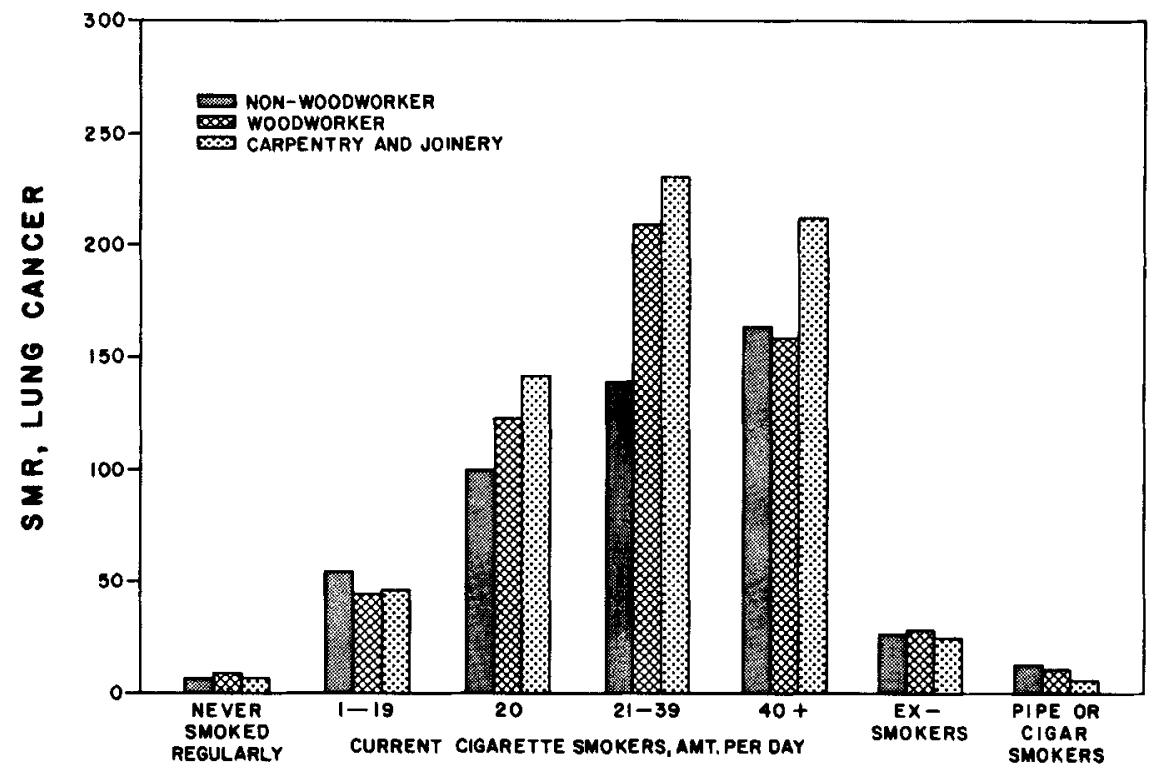

Fig. 1. Standardized mortality ratios for lung cancer, by occupation and smoking habits. All categories are relative to nonwoodworkers who were current smokers of 20 cigarettes per day $(=100)$.

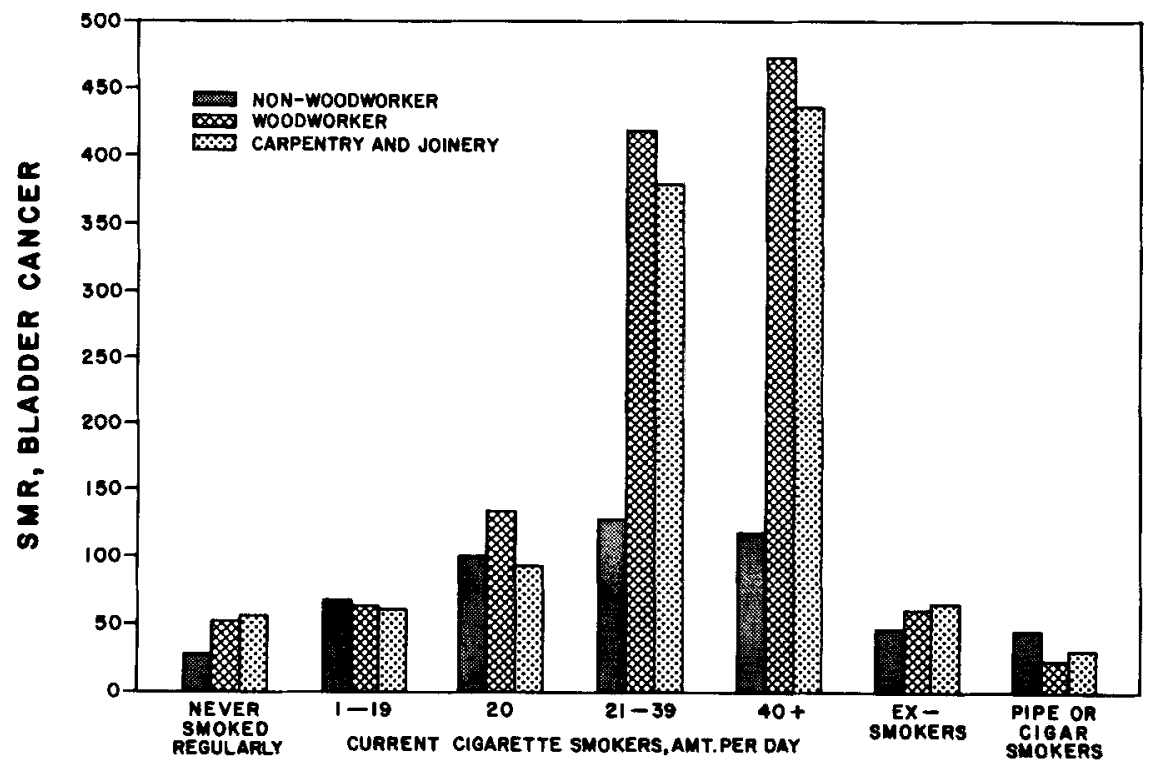

Fig. 2. Standardized mortality ratios for bladder cancer, by occupation and smoking habits. All categories are relative to nonwoodworkers who were current smokers of 20 cigarettes per day $(=100)$. 


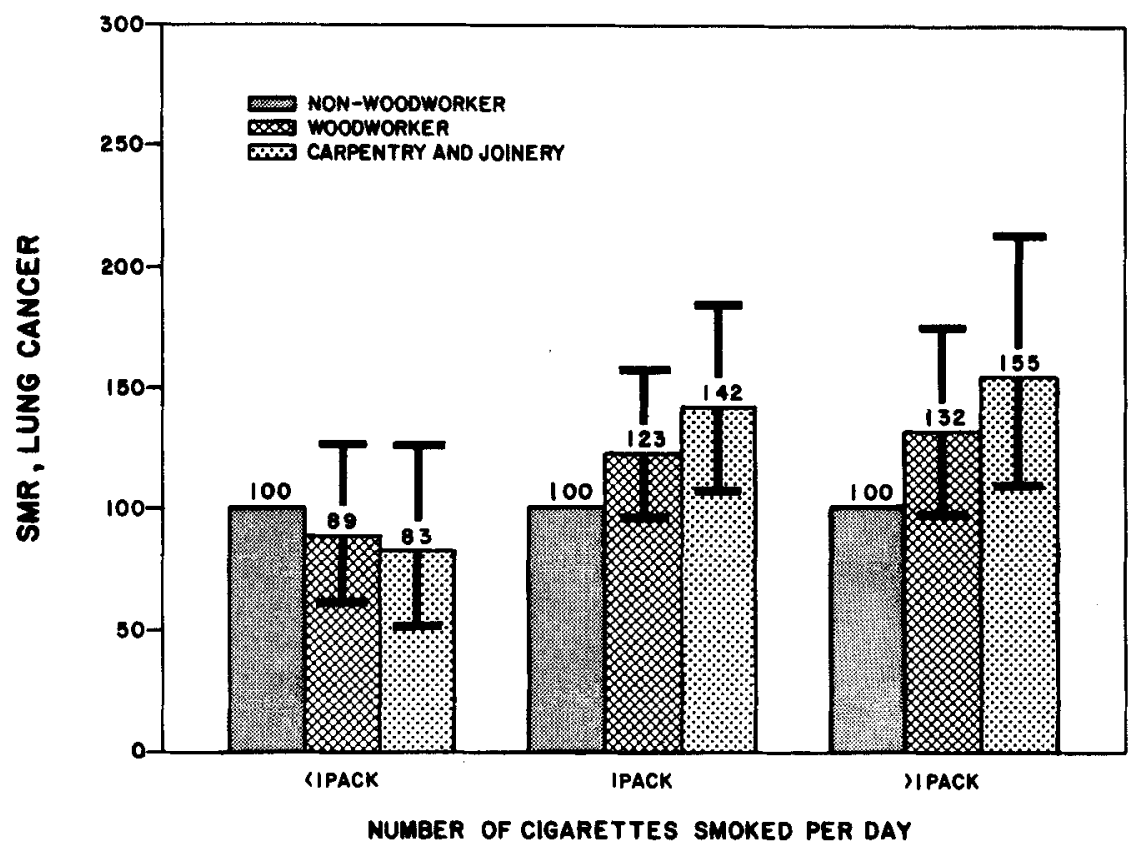

Fig. 3. Standardized mortality ratios for lung cancer, by occupation and smoking habits, for current cigarette smokers or nonsmokers only. Within each smoking class, all categories are relative to nonwoodworkers $(=100)$.

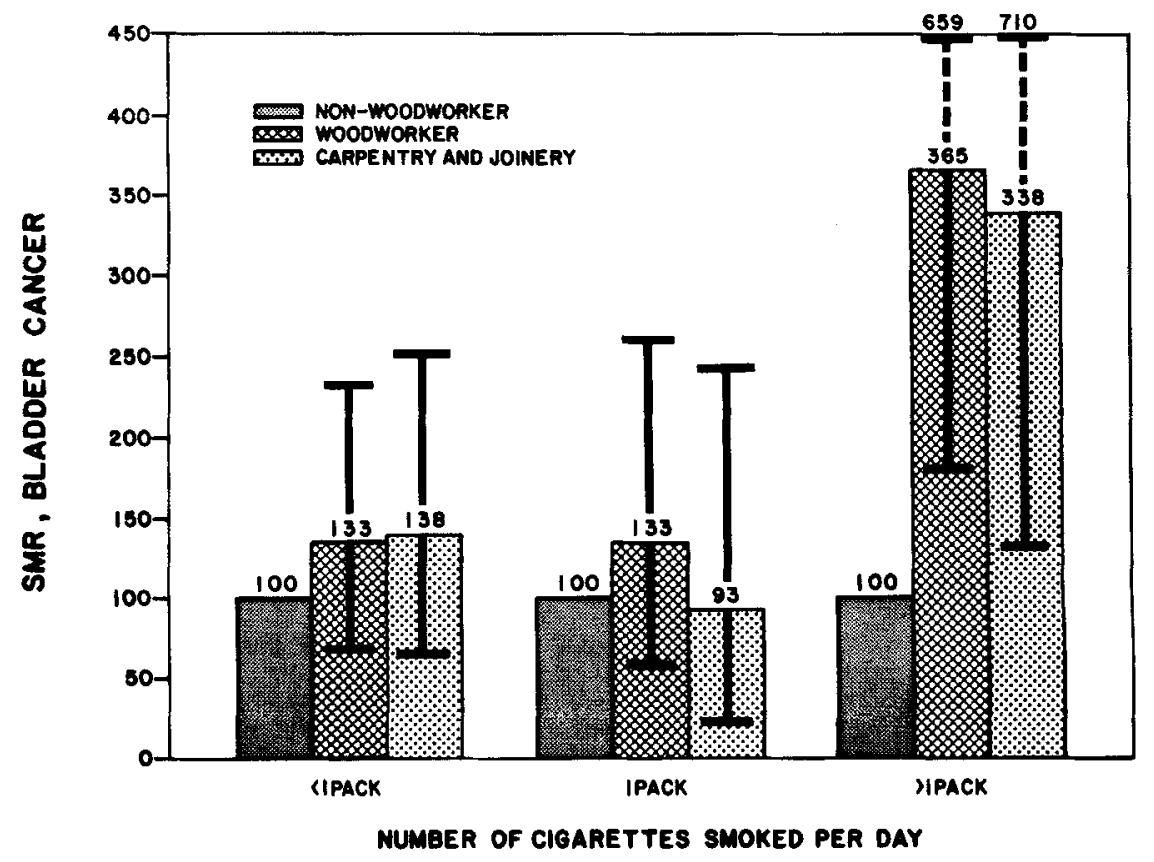

Fig. 4. Standardized mortality ratios for bladder cancer, by occupation and smoking habits, for current cigarette smokers or nonsmokers only. Within each smoking class, all categories are relative to nonwoodworkers $(=100)$. 
TABLE VI. Adjustment for Smoking Habits-All Woodworkers

\begin{tabular}{|c|c|c|c|c|}
\hline \multirow{3}{*}{$\begin{array}{l}\text { Cause of } \\
\text { death }\end{array}$} & \multicolumn{4}{|c|}{ Adjusted for } \\
\hline & \multicolumn{2}{|c|}{ Age only } & \multicolumn{2}{|c|}{ Age, smoking } \\
\hline & SMR & $P$ & SMR & $P$ \\
\hline \multicolumn{5}{|l|}{ Cancers } \\
\hline Stomach & 149 & 0.007 & 137 & 0.04 \\
\hline Nasal cavity & 200 & 0.3 & 250 & 0.19 \\
\hline Lung & 113 & 0.09 & 114 & 0.08 \\
\hline Lung $^{\mathrm{a}}$ & 120 & 0.04 & 122 & 0.03 \\
\hline Bladder & 142 & 0.04 & 147 & 0.03 \\
\hline Bladder $^{\mathrm{a}}$ & 134 & 0.12 & 142 & 0.08 \\
\hline Colon-rectum & 75 & 0.01 & 69 & 0.003 \\
\hline Colon-rectum ${ }^{a}$ & 78 & 0.06 & 69 & 0.01 \\
\hline Coronary heart disease & 95 & 0.049 & 95 & 0.045 \\
\hline
\end{tabular}

${ }^{a}$ Carpenters only.

Our observed lung cancer mortality ratio of 113 among woodworkers as a group is also similar to that reported for woodworkers in the U.K. (SMR $=113, p<0.05$ [Logan, 1982]). A much stronger relationship was reported by Harrington et al in an analysis of occupations mentioned on death certificates in coastal Georgia [Harrington et al, 1978]. An overall excess was not seen in the 12 counties studied, but in a subgroup of the smaller counties, a threefold excess lung cancer death rate was observed in sawmill, lumber, and forestry workers, as well as pulp and paper workers and carpenters. A separate case-control study in a nearby region of Florida found increased risks of lung cancer among workers employed in lumber/wood industries, and especially among workers with reported exposure to wood dust [Blot et al, 1982]. By contrast, an analysis of death certificates and registry reports in Los Angeles County failed to list carpenters among the 24 occupations having significantly elevated SMRs [Menck and Henderson, 1976]. The SMR for the aggregated lumber-woodfurniture industries was 114 (not significant). So far as we know, ours was the only study mentioned in which smoking habits were explicitly accounted for.

Milham has studied the mortality experience of the AFL-CIO United Brotherhood of Carpenters and Joiners of America in 1969-70 [Milham, 1974]; the study was updated for 1972-73. The results, which were based on over 32,000 deaths in a population of about 700,000 men, showed small overall increases in cancer of the lung, small intestine, and prostate; lung cancer rates were particularly high in acoustical tile applicators and insulators, probably related to asbestos exposure. Of the three categories of woodworkers in our study, carpenters undoubtedly have the greatest potential exposure to asbestos, which could explain why their lung cancer risk is greatest. On the other hand, much of their asbestos exposure occurs indirectly (as bystanders, rather than directly as asbestos installers), and their work is often done in the open air with natural ventilation. Both of these factors would tend to make their exposures less than those of insulation workers, so that their lung cancer mortality rates would be correspondingly lower.

In several population-based studies, increased risks for stomach cancer have been observed among various wood-related occupations. In Milham's Washington state study [Milham, 1976], stomach cancer was significantly elevated in carpenters $(P M R=128)$, plywood workers $(P M R=153)$, and loggers $(P M R=120)$. Stomach cancer was also slightly elevated in the Carpenters Union study $(\mathrm{SMR}=112, \mathrm{p}<0.05)$. 
A similar mortality ratio for sawyers, 111, was reported in the U.K. 1951 RegistrarGeneral's report [Logan, 1982]. In a case-control study at Roswell Park Memorial Institute, in which relative risks were computed for various occupational groups, carpenters experienced a significantly higher risk $(R R>2.2)$ for stomach cancer [Decoufle et al, 1977].

The stomach cancer excess in our study could not be attributed to cigarette smoking or other confounding factors. Milham [1976] suggested that "ingested (or inhaled and swallowed) wood particles may cause gastric cancer," and that use of chewing tobacco by loggers and mill workers may also be a factor. If, as we have suggested in the above, our observed lung cancer excess is due in part to asbestos exposure, then that may be a plausible explanation for stomach cancer as well, since asbestos has been implicated in the etiology of gastrointestinal cancers [Selikoff et al, 1979]. Our finding applies only to stomach cancer and not to colon-rectum cancer, which we found to be significantly lower among woodworkers. In a much smaller study of patternworkers in the automotive industry, by contrast, a high rate of colon cancer was reported [Swanson and Belle, 1982].

Even though the number of nasal cancers observed is too small for meaningful statistical analysis, it is twice the number expected (three times expected, if based on the carpenters and joiners alone). Nasal cavity cancer might be considered the classical tumor of the furniture making industry, according to studies in a dozen or more countries [Wills, 1982]. That it was not observed among our furniture-cabinetry group here is likely to be due to the small size of the sub-cohort, among whom $<0.1$ case would be expected over the entire 12-year observation period.

Bladder cancer was consistently elevated in all three of our subgroups. Whereas bladder cancer was among the highest cancers in woodworkers in the U.K. (SMR $=16$, $\mathrm{p}<0.01$ [Logan, 1982]), few other previous studies have reported bladder cancer among any of the woodworking trades [Wynder and Goldsmith, 1977], and at least one study failed to find any increased risk for woodworkers [Cole et al, 1972]. This is therefore an intriguing observation which needs further study.

Based on numerous earlier reports, including both case-control [Petersen and Milham, 1974] and population studies [Milham, 1976], we expected to find an increase in Hodgkin disease. No such increase was observed (although one death occurred in a furniture worker, with 0.3 expected). Hodgkin disease was also low among U.K. woodworkers [Logan, 1982], so our study is more consistent with the British experience. With regard to other lymphatic system cancers, there were a total of 17 cases of lymphoma, lymphosarcoma, reticulosarcoma, and multiple myeloma, which were significantly fewer than expected $(S M R=70)$. On the other hand, we found an excess of leukemias, particularly among carpenters $(S M R=140)$. If confirmed, this would be the first report of increased leukemia in woodworkers.

\section{Other Causes of Death}

The slightly lower rates of coronary heart disease in this population, relative to the NWW, gives us confidence that the various cancer mortality ratios are not artifacts. The higher accidental death rates, particularly among lumber and sawmill workers, were not surprising, as this is well known to be a high risk group. However, we have no ready explanation for the greater than $50 \%$ increase in pneumonia among carpenters and joiners, which is contrary to the significantly lower rate observed in the carpenters' union [Milham, 1974]. 


\section{CONCLUSIONS}

We have reported standardized mortality ratios for a cohort of over 10,000 woodworkers, initially healthy, who were followed for up to a 12-year period. The comparison or control group was the larger cohort of nearly half a million men in 25 states from whom the woodworkers were drawn. Age-adjusted rates of death from all causes and from all cancers were not higher in WW than NWW. Excess rates were observed for cancers of the lung, stomach, and bladder, as well as nonmelanoma skin cancer and leukemia. WW experienced significantly decreased rates of colon-rectum cancer and coronary heart disease. Our cancer findings are consistent with a number of population-based studies on woodworkers, defined in various ways, but are inconsistent with others, notably with respect to Hodgkin disease.

Our results could not be explained by cigarette smoking habits, which were slightly lower in WW as a group. If anything, there is some evidence to suggest an interaction between employment in woodworking trades and heavy cigarette smoking. Carpenters and joiners, whose risks were the most pronounced of the three subgroups studied, are most likely to be exposed to asbestos, which we suggest as a possible explanation for a portion of the excess lung and stomach cancer. The bladder cancer observation is not a new one, but merits further study by others.

\section{REFERENCES}

Acheson ED (1976): Nasal cancer in the furniture and boot and shoe manufacturing industries. Prev Med 5:295-315.

Acheson ED, Cowdell RH, Rang EH (1981): Nasal cancer in England and Wales: An occupational survey. Br J Ind Med 38:218-224.

Blot WJ, Davies JE, Brown LM, Nordwall CW, Buiatti E, Ng A, Fraumeni JF Jr (1982): Occupation and the high risk of lung cancer in northeast Florida. Cancer 50:364-371.

Brinton LA, Blot WJ, Stone BJ, Fraumeni JF Jr (1977): A death certificate analysis of nasal cancer among furniture workers in North Carolina. Cancer Res 37:3473-3474.

Cecchi F, Buiatti E, Kreibel D, Nastasi L, Santucci M (1980): Adenocarcinoma of the nose and paranasal sinuses in shoemakers and woodworkers in the province of Florence, Italy (1963-77). Br J Ind Med 37:222-225.

Cole P, Hoover R, Friedell G (1972): Occupation and cancer of the lower urinary tract. Cancer 29:12501260.

Decoufle P, Stanislawczyk K, Houten L, Bross IDJ, Viadana E (1977): “A Retrospective Survey of Cancer in Relation to Occupation." DHEW Publ. No. (NIOSH) 77-178. Washington, DC: U.S. Government Printing Office.

Elwood JM (1981): Wood exposure and smoking: Association with cancer of the nasal cavity and paranasal sinuses in British Columbia. CMA Journal 124:1573-1577.

Fonte R, Grigis L, Grigis P, Franco G (1982): Chemicals and Hodgkin's disease. Lancet 2:50.

Greene MH, Brinton LA, Fraumeni JF Jr, D'Amico R (1978): Familial and sporadic Hodgkin's disease associated with occupational wood exposure. Lancet 2:626-627.

Hadfield EH (1972): Cancer hazard from wood dust and in the boot and shoe industry. Ann Occup Hyg 15:39.

Hadfield EH, Macbeth RG (1971): Adenocarcinoma of ethmoids in furniture workers. Ann Otol Rhinol Laryngol 80:699-703.

Hammond EC (1966): "Smoking in Relation to the Death Rates of One Million Men and Women." National Cancer Institute Monograph 19. Washington, DC: Department of Health, Education and Welfare, Public Health Service, National Cancer Institute.

Hammond EC, Garfinkel L (1969): Coronary heart disease, stroke, and aortic aneurysm. Factors in the etiology. Arch Environ Health 19:167-182.

Hardell L (1979): Malignant lymphoma of histiocytic type and exposure to phenoxyacetic acids or chlorophenols. Lancet 1:55-56. 
Hardell L, Sandstrom A (1979): Case-control study: Soft-tissue sarcomas and exposure to phenoxyacetic acids or chlorophenols. Br J Cancer 39:711-717.

Harrington JM, Blot WJ, Hoover RN, Housworth WJ, Heath CW, Fraumeni JF Jr (1978): Lung cancer in coastal Georgia: A death certificate analysis of occupation. J Natl Cancer Inst 60:295-298.

IARC Monographs on the Evaluation of the Carcinogenic Risk of Chemicals to Humans (1981): Vol 25, "Wood, Leather and Some Associated Industries." Lyon: IARC.

Logan WPD (1982): “Cancer Mortality by Occupation and Social Class, 1851-1971." IARC Scientific Publications No. 36; Studies on Medical and Population Subjects. No. 44. London: Her Majesty's Stationery Office.

Menck HR, Henderson BE (1976): Occupational differences in rates of lung cancer, $J$ Occup Med 18:797-801.

Milham S Jr (1974): "A Study of the Mortality Experience of the AFL-CIO United Brotherhood of Carpenters and Joiners of America, 1969-1970." DHEW Publ No. (NIOSH) 74-129, Springfield, VA: National Technical Information Service.

Milham S Jr (1976): “Occupational Mortality in Washington State: 1950-1971." Washington, DC: HEW Publ No. (NIOSH) 76-175-A.

Milham S Jr, Hesser JE (1967): Hodgkin's disease in woodworkers. Lancet 2:136-137.

Olsen J, Sabroe S (1979): A follow-up study of non-retired and retired members of the Danish carpenter/ cabinet makers trade union. Int J Epidemiol 8:375-382.

Petersen GR, Milham S Jr (1974): Hodgkin's disease mortality and occupational exposure to wood. J Natl Cancer Inst 53:957-958.

Roush G, Meigs J, Kelly J, Flannery J, Burdo H (1980): Sinonasal cancer and occupation: A casecontrol study. Am J Epidemiol 111:183-193.

Selikoff IJ, Hammond EC, Seidman H (1979): Mortality experience of insulation workers in the United States and Canada, 1943-1976. Ann NY Acad Sci 330:91-116.

Swanson GM, Belle SH (1982): Cancer morbidity among woodworkers in the U.S. automotive industry. J Occup Med 24:315-319.

Swenberg JA, Kerns WD, Mitchell RI, Gralla EJ, Pavkov KL (1980): Induction of squamous cel] carcinomas of the rat nasal cavity by inhalation exposure to formaldehyde vapor. Cancer Res 40:3398-3401.

Wills JH (1982): Nasal carcinoma in woodworkers: A review. J Occup Med 24:526-530.

Wynder EL, Goldsmith R (1977): The epidemiology of bladder cancer: A second look. Cancer 40:12461268. 